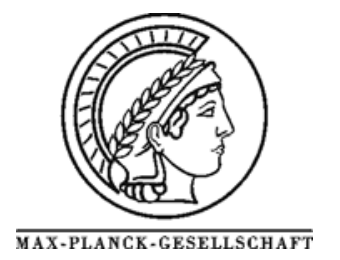

Journal of Catalysis 241 (2006) 14-19

\title{
Growth and structural stability of well-ordered PdZn alloy nanoparticles
}

\author{
S. Penner ${ }^{\text {* }}$, B. Jenewein ${ }^{1}$, H. Gabasch ${ }^{1,2}$, B. Klötzer ${ }^{1}$, D. Wang ${ }^{2}$, A. Knop-Gericke ${ }^{2}$, R. Schlögl ${ }^{2}$, \\ K. Hayek ${ }^{1}$ \\ ${ }^{1}$ Institute of Physical Chemistry, University of Innsbruck, Innrain 52a, A-6020 Innsbruck, Austria \\ ${ }^{2}$ Department of Inorganic Chemistry, Fritz-Haber-Institute of the MPG, Faradayweg 4-6, 14195 Berlin, Germany \\ * Corresponding author: e-mail simon.penner@uibk.ac.at, phone +43 512507 5056, fax +43 5125072925
}

Received: 16 february 2006, revised 3 April 2006, accepted 6 April 2006,available online 15 May 2006

\begin{abstract}
Despite many recent attempts to unravel the structure of novel PdZn alloys, promising catalysts in methanol steam reforming, a detailed study on the formation of Pd-Zn alloy particles and of their structural and thermal stability is still missing. We take advantage of the unique properties of epitaxially grown $\mathrm{Pd}$ particles embedded in layers of amorphous $\mathrm{ZnO}$ and mechanically stabilized by $\mathrm{SiO}_{2}$, and present an electron microscopy study of the preparation of well-ordered PdZn alloy nanoparticles at surprisingly low reduction temperatures. They are formed by topotactic growth on the surface of the Pd nanoparticles and are structurally and thermally stable in a broad temperature regime ( $473-873 \mathrm{~K})$. At and above $873 \mathrm{~K}$, partial decomposition of $\mathrm{PdZn}$ and beginning interaction with the $\mathrm{SiO}_{2}$ support has been observed.
\end{abstract}

Keywords: Thin film model catalyst, hydrogen reduction, alloy formation, electron microscopy, selected area electron diffraction

\section{Manuscript}

Much recent effort has been invested in the development of suitable catalysts for methanol steam reforming ${ }^{1-}$ ${ }^{15}$ as this is one of the most promising processes for hydrogen production with a high hydrogen-to-carbon ratio ${ }^{16}$. $\mathrm{Cu} / \mathrm{ZnO}$ catalysts have been commercially used to produce hydrogen with high selectivity and activity ${ }^{2-6}$, but they suffer from deactivation at reaction temperatures above 573 $\mathrm{K}^{17}$. Recently, novel $\mathrm{Pd} / \mathrm{ZnO}$ systems $^{3-15}$ (as well as $\mathrm{Pd} / \mathrm{Ga}_{2} \mathrm{O}_{3}$ and $\mathrm{Pd} / \mathrm{In}_{2} \mathrm{O}_{3}{ }^{18,19}$ ) have attracted more attention because of their enhanced long-term and thermal stability ${ }^{20,21}$. As unsupported pure Pd exhibits only a poor selectivity ${ }^{22}$, the observed high activity and selectivity for $\mathrm{CO}_{2}$ formation was ascribed to the formation of distinct $\mathrm{PdZn}$, PdIn and PdGa alloys upon reductive activation at elevated temperatures ${ }^{18}$. Best characterized is the $\mathrm{Pd} / \mathrm{ZnO}$ system, where alloy formation has been studied and confirmed by X-ray diffraction $(\mathrm{XRD})^{18,23}$, temperature-programmed reduction (TPR) ${ }^{18,23}$ and X-ray and ultraviolet photoelec- tron spectroscopy (XPS and UPS) ${ }^{24-26}$. Iwasa et al. ${ }^{23}$ observed PdZn alloy formation upon reduction at very low $\mathrm{T}$ ( $\geq 473 \mathrm{~K}$ ). Density functional studies revealed the close relationship between the electronic structure of $\mathrm{PdZn}$ and $\mathrm{Cu}$-based catalysts giving rise to a similar catalytic performance in methanol steam reforming ${ }^{27,28}$. Comparatively few studies have been carried out on the structural characterization of the PdZn alloys by electron microscopy, and these were limited to overview imaging of powder catalysts in the as-prepared state and after hydrogen reduction, thereby mainly supporting XRD measurements ${ }^{29,30}$. The $\mathrm{Pd}-\mathrm{Zn}$ system is known to form several stable bulk alloy phases $^{31}$. The most important and thermally most stable is the PdZn ( $\beta 1)$ phase, which crystallizes in a tetragonal (AuCu-type) $\mathrm{L}_{0}$ structure $^{32}$. A key point for understanding the catalytic pecularities of the above-mentioned $\mathrm{Pd}-\mathrm{Zn}$ alloy particles is also to determine their surface composition. Recent experiments in our laboratory ${ }^{33}$ show that a well-ordered $(6 \times 4 / \sqrt{ } 3) \mathrm{Pd}-\mathrm{Zn}$ layer forms on $\mathrm{Pd}(111)$ under UHV conditions at elevated temperature. 
Despite the importance of PdZn alloys for hydrogen production by steam reforming, detailed transmission electron microscopy (TEM) studies of their morphology and structure are not yet available. The aim of this study is therefore to exploit the capabilities of modern electron microscopes to resolve the atomic structure of catalysts and to start from well defined Pd particles, epitaxially grown on $\mathrm{NaCl}(001)$ cleavage faces and subsequently embedded in a layer of $\mathrm{ZnO}$, to prepare distinct PdZn alloys. We shall be able to present the first high-resolution images of welldefined PdZn alloy particles and to propose a mechanism of their formation, as well as detailed information on their thermal and structural stability.

Pd metal was deposited by electron-beam evaporation onto a freshly-cleaved $\mathrm{NaCl}(001)$ plane at a base pressure of $10^{-4} \mathrm{~Pa}$ and a substrate temperature of $623 \mathrm{~K}$. Under these experimental conditions, the deposition of $\mathrm{Pd}$ films of about $0.5 \mathrm{~nm}$ nominal thickness results in well-shaped $\mathrm{Pd}$ particles about $5 \mathrm{~nm}$ in size. Subsequently, the Pd particles were covered by a layer of amorphous $\mathrm{ZnO}$ at $523 \mathrm{~K}$ template temperature and mechanically stabilized by a supporting layer of amorphous $\mathrm{SiO}_{2}$ (nominal thickness: $25 \mathrm{~nm}$ ), deposited at room temperature. $\mathrm{NaCl}$ was subsequently removed by dissolution in distilled water and after careful rinsing the resulting thin films were dried and mounted on gold grids for electron microscopy. Reductive treatments ( 1 bar $\mathrm{H}_{2}$ for $1 \mathrm{~h}$ ) were performed in parallel in a flow system and a circulating batch reactor in the temperature range between 473 and $873 \mathrm{~K}$. Structural and morphological changes were followed by (high-resolution) electron microscopy (HRTEM), selected area electron diffraction (SAED) and energy-dispersive X-ray spectroscopy (EDXS). The electron micrographs were taken with a ZEISS EM 10C, and with a CM FEG microscope equipped with a Gatan image filter GIF100.
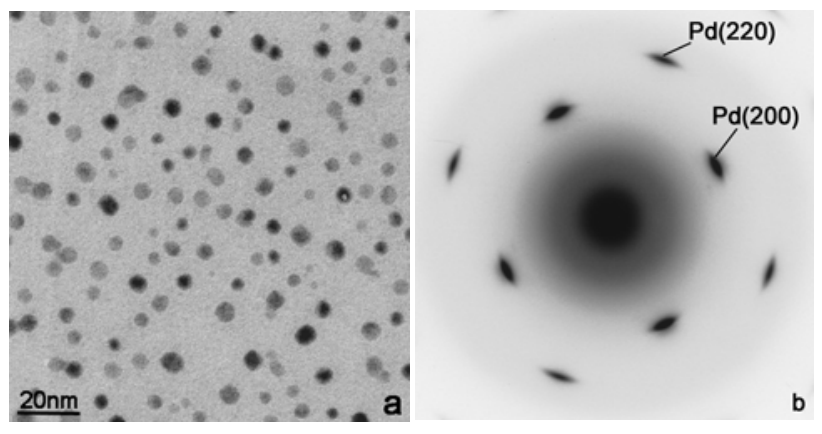

Figure 1: (a) TEM overview of as-deposited Pd particles and $\mathrm{ZnO} / \mathrm{SiO}_{2}$ support, (b) corresponding SAED pattern.

The TEM overview in Fig. 1a shows the as-deposited state of the Pd catalyst, to which we reference all structural alterations occurring upon reductive activation. The $\mathrm{Pd}$ particles are visible as dark and grey dots with a mean diameter of $\sim 5 \mathrm{~nm}$. A particle density of around $6.8 \times 10^{7}$ particles $/ \mathrm{cm}^{2}$ was estimated by evaluating a number of TEM images from different parts of the sample. The dark particles are perfectly aligned along the Bragg orientation, the grey ones slightly tilted out of the respective Bragg position. Most particles exhibit square or rectangular shapes, whereas some have more rounded outlines. Weak-beam dark field images of the corresponding alumina-based Pd thin film catalysts revealed the cuboctahedral habit of these particles $^{34}$. Their almost perfect relative orientation with respect to the former $\mathrm{NaCl}(001)$ single crystal substrate is confirmed by the SAED pattern (Fig. 1b), exhibiting exclusively reflections of the fcc structure of the Pd particles oriented along the [001] zone axis, i.e. $\operatorname{Pd}(200)$ and $\operatorname{Pd}(220)$ spots. No reflections arising from other orientations are present. HRTEM images (Fig. 2) of cuboctahedral particles mainly show (200) lattice fringes of fcc $\mathrm{Pd}$ $\left[\mathrm{d}_{200}(\mathrm{Pd})=0.1945 \mathrm{~nm}\right]$, including an angle of $45^{\circ}$ with the (111) cuboctaeder faces ${ }^{34}$. Hence, most Pd particles exhibit (001) base planes perpendicular to the electron beam. Both the $\mathrm{ZnO}$ and the $\mathrm{SiO}_{2}$ support are amorphous in the asgrown state. The amount of deposited $\mathrm{ZnO}$ was verified by EDXS to be close to the amount of deposited Pd.

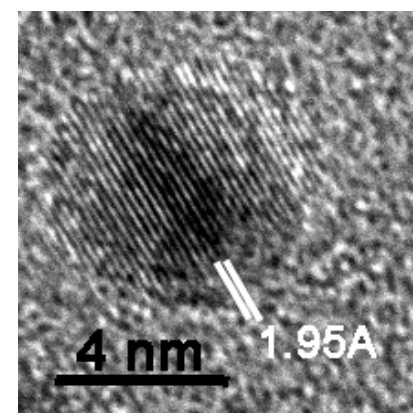

Figure 2: HRTEM image of an as-grown Pd particle exhibiting (200) lattice fringes.

No significant changes in particle structure or morphology were noticed upon reduction at temperatures below $473 \mathrm{~K}$ (1 bar hydrogen for $1 \mathrm{~h}$ ). However, considerable alterations in both the morphology and composition are introduced if the reduction temperature is raised to $523 \mathrm{~K}$ (Fig. 3). The particle size is slightly increased compared to the as-deposited state $(5.3 \mathrm{~nm}$ mean diameter, particle density: $5.6 \times 10^{7}$ particles $/ \mathrm{cm}^{2}$ ), and recrystallization has occurred. A major part of the particles show randomly arranged sharp edges (denoted "A" in Fig. 3a), while square and rectangular particles with sharp outlines are also present (denoted "B" in Fig. 3a). This morphology is in striking contrast to both the as-grown state of this catalyst (Fig. 1a) and the state of a $\mathrm{Pd} / \mathrm{SiO}_{2}$ reference catalyst without $\mathrm{ZnO}$, but treated under otherwise identical conditions (1 bar $\mathrm{H}_{2}$ for $1 \mathrm{~h}$ at $523 \mathrm{~K}$, see Figs. $3 \mathrm{c}$ and d), which is discussed below. SAED patterns (Fig. 3b) and high-resolution images (Fig. 4) confirm the observed morphology changes. The SAED patterns of Fig. 3b show a "doubling" of both the $\mathrm{Pd}(200)$ and the $\mathrm{Pd}(220)$ spots, i.e. new reflections arise at $\mathrm{d} \sim 0.144 \mathrm{~nm}$ and $\mathrm{d} \sim 0.205 \mathrm{~nm}$, and four new spot reflections appear at $\sim 0.291 \mathrm{~nm}$, rotated by $45^{\circ}$ with respect to the Pd (200) spots. These new reflections perfectly 


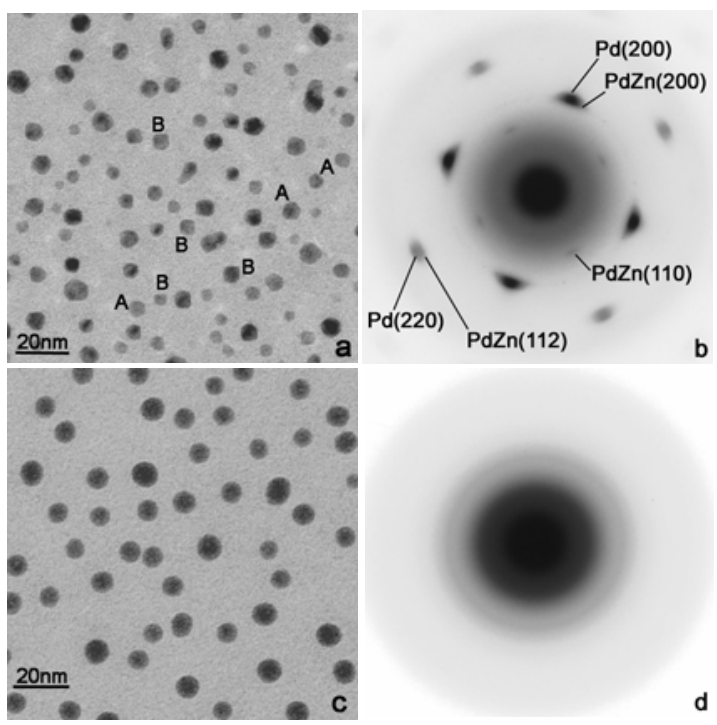

Figure 3: (a) TEM overview of the $\mathrm{Pd} / \mathrm{ZnO} / \mathrm{SiO}_{2}$ catalyst after reduction in 1 bar hydrogen at $523 \mathrm{~K}$ for $1 \mathrm{~h}$, (b) corresponding SAED pattern; (c) TEM overview of the $\mathrm{Pd} / \mathrm{SiO}_{2}$ reference catalyst after reduction in 1 bar hydrogen at $523 \mathrm{~K}$ for $1 \mathrm{~h}$, (d) corresponding SAED pattern.

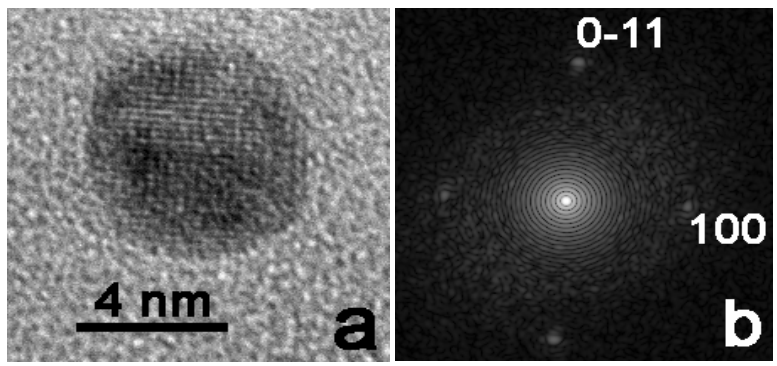

Figure 4: (a) HRTEM image of a single-crystalline PdZn particle on its [011] zone axis, (b) corresponding FFT.

match the (112), (200) and (110) reflections of the tetragonal $\mathrm{PdZn}$ alloy phase $\left(\mathrm{L1}_{0} \text { AuCu-type structure }\right)^{32}$ $\left(\mathrm{d}_{112}(\mathrm{PdZn})=0.1449 \mathrm{~nm}, \mathrm{~d}_{200}(\mathrm{PdZn})=0.205 \mathrm{~nm}\right.$, $\left.\mathrm{d}_{110}(\mathrm{PdZn})=0.290 \mathrm{~nm}\right)$, which was formed to some extent during reductive activation even at $473 \mathrm{~K}$. We emphasize that this newly formed alloy phase grows in almost perfect crystallographic relationship to the underlying Pd lattice (Pd [100] // PdZn [100]). This result is further corroborated by parallel high-resolution imaging. Fig. 4 shows a single PdZn alloy particle along with its fast Fourier transform (FFT). According to the FFT, the lattice fringes can be addressed to the (100) and (0-11) distances of the tetragonal PdZn crystal structure ${ }^{32}$. Hence, the particle is oriented along its [011] zone axis. Similar effects have already been observed on the corresponding $\mathrm{Pt} / \mathrm{SiO}_{2}{ }^{35}$ and $\mathrm{Pt} / \mathrm{CeO}_{2}{ }^{36}$ systems. On the $\mathrm{Pd} / \mathrm{SiO}_{2}$ reference catalyst without $\mathrm{ZnO}$, which was reduced under otherwise identical conditions, the introduction of higher-indexed facets, manifested as a rounding of particles in $\mathrm{TEM}^{34}$ and a considerable increase of particle size due to coalescence was observed (Fig. 3c), which is in strong contrast to the effects observed on $\mathrm{Pd} / \mathrm{ZnO} / \mathrm{SiO}_{2}$ (Fig. 3a). Compared to the $\mathrm{Pd} / \mathrm{ZnO} / \mathrm{SiO}_{2}$ catalyst, the SAED patterns of $\mathrm{Pd} / \mathrm{SiO}_{2}$ catalysts after reduction at $523 \mathrm{~K}$ (Fig. 3b) clearly reflect a trend towards amorphous structures, which may be interpreted in terms of $\mathrm{Pd}$ hydride formation ${ }^{37}$. From the comparison of Figs. $3 a$ and $b$ on the one hand and Figs $3 \mathrm{c}$ and $\mathrm{d}$ on the other hand, it is obvious that the above-discussed recrystallization of the $\mathrm{Pd}$ particles in contact with $\mathrm{ZnO}$ must be closely associated to the process of alloy formation. Thus, adding $\mathrm{ZnO}$ to the $\mathrm{Pd} / \mathrm{SiO}_{2}$ system (i) structurally stabilizes the Pd particles by $\mathrm{Pd}-\mathrm{Zn}$ alloy formation compared to $\mathrm{Pd} / \mathrm{SiO}_{2}$ and (ii) prevents the formation of an amorphous hydride phase. Furthermore, from this protection against hydride formation by the presence of $\mathrm{ZnO}$ one can deduce that already at low reduction temperatures the particles are covered by a shell of well-ordered PdZn alloy. This growth mechanism is confirmed by the fact that at $\mathrm{T} \leq 523 \mathrm{~K}$ metallic Pd is still present and by the perfect epitaxial relationship between $\mathrm{Pd}$ and PdZn. Most likely, a metastable PdZn alloy skin is formed before alloying proceeds into deeper regions of the Pd particles. Fig. 4 shows a HR image of a single PdZn alloy particle in the state of complete transformation already after reduction at $523 \mathrm{~K}$. Since the SAED pattern shows metallic $\mathrm{Pd}$ remaining on the catalyst, complete PdZn particles as shown in Fig. 4 are still the minority species after $523 \mathrm{~K}$ reduction.

This "partially alloyed" state of the catalyst is stable up to $523 \mathrm{~K}$. After reduction above $600 \mathrm{~K}$, the Pd reflections vanish and only alloy-induced diffraction spots remain. TEM images taken after reduction at $723 \mathrm{~K}$ (Fig. 5a) reveal that the particle size has again slightly increased (mean diameter $5.5 \mathrm{~nm}$, particle density: $5.2 \times 10^{7}$ particles $/ \mathrm{cm}^{2}$ ), confirming the high thermal stability of the PdZn alloy in comparison to the as-grown state and the state after reduction at $523 \mathrm{~K}$. SAED patterns (Fig. 5b) show broadened PdZn reflections indicating a slight azimuthal disorder of the alloy particles. However, as no higher-order reflections of the tetragonal alloy structure are visible, it is clear that no additional particle zone axes contribute to the diffraction pattern. This underlines the high structural stability of the completed Pd-Zn alloy particles.

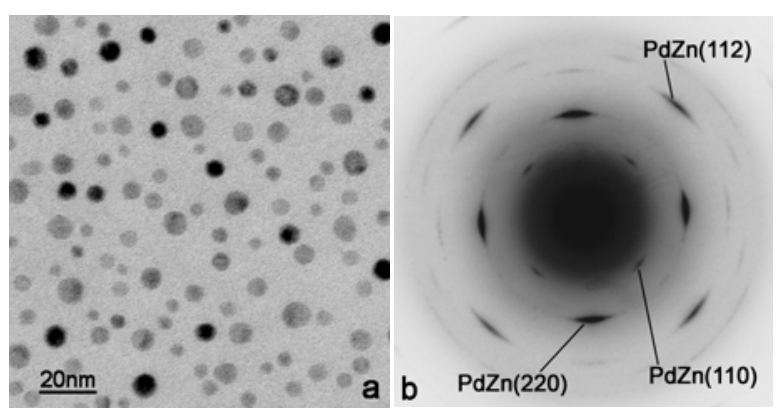

Figure 5: (a) TEM overview of the $\mathrm{Pd} / \mathrm{ZnO} / \mathrm{SiO}_{2}$ thin film catalyst after reduction in 1 bar hydrogen at $723 \mathrm{~K}$ for $1 \mathrm{~h}$, (b) corresponding SAED pattern. 

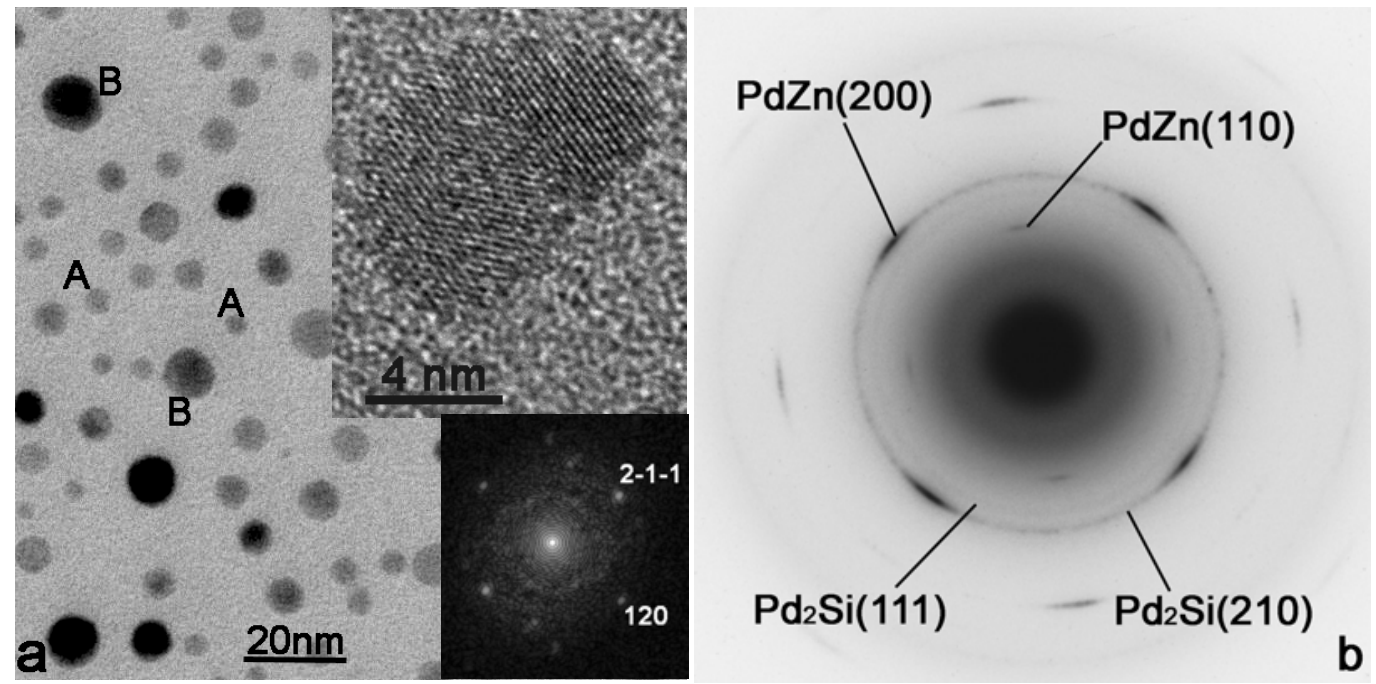

Figure 6: State of the $\mathrm{Pd} / \mathrm{ZnO} / \mathrm{SiO}_{2}$ catalyst after reduction in 1 bar $\mathrm{H}_{2}$ at $873 \mathrm{~K}$ for $1 \mathrm{~h}$. (a) TEM overview, (b) SAED pattern. Inset: HRTEM image of a $[2,-1,-5]$ oriented $\mathrm{Pd}_{2} \mathrm{Si}$ particle with its FFT.

By reduction at and above $873 \mathrm{~K}$ (Figs. 6a and b), again some structural alterations are observed. The majority of particles did not undergo coalescence but appear thermally and structurally stable even at $\geq 873 \mathrm{~K}$ (denoted "A" in Fig. 6a). Nevertheless, some considerably larger particles (denoted "B" in Fig. 6a) were formed, obviously by consuming closely neighboured particles. It is worth to notice that the sharp-angled particles have almost completely vanished and most particles now exhibit more rounded outlines. Increasing disorder is also evidenced by the SAED patterns in Fig. 6b. The PdZn (110) and (200) spots appear broadened and faint, pointing to an increasing loss of orientational order and/or partial decomposition of the $\mathrm{PdZn}$ alloy. In addition, the formation of a $\mathrm{Pd}_{2} \mathrm{Si}$ alloy phase is documented by the SAED pattern (Fig. 6b) and by highresolution imaging (inset in Fig. 6a), indicating that at about $900 \mathrm{~K}$ the stability limit of the $\mathrm{Pd} / \mathrm{ZnO} / \mathrm{SiO}_{2}$ catalyst is reached. Weak $\mathrm{Pd}_{2} \mathrm{Si}$ (111) and (210) reflections, the latter overlapping with the broadened $\operatorname{PdZn}(200)$ spots, appear in the electron diffraction patterns. The HRTEM image of a single $\mathrm{Pd}_{2} \mathrm{Si}$ alloy particle (along with its FFT) as shown in the inset of Fig. 6a indicates that the particle is oriented along its [2-1-5] zone axis. The state of the catalyst after reduction at $873 \mathrm{~K}$ can therefore be characterized as a coexistence of $\mathrm{PdZn}$ and $\mathrm{Pd}_{2} \mathrm{Si}$ alloy phases.

In line with previous studies on PdZn formation ${ }^{8,12-}$ ${ }^{14}$, the present electron microscopy study unambiguously reveals the onset of the formation of a tetragonal $\mathrm{PdZn}$ phase upon reduction at $\mathrm{T} \geq 473 \mathrm{~K}$. The formation of the alloy phase proceeds most likely via topotactic formation of $\mathrm{PdZn}$ on top of the Pd particles. This growth mechanism is probably favoured by the relatively small mismatch of the lattice constants of fcc $\mathrm{Pd}(0.388 \mathrm{~nm})$ and tetragonal PdZn $(0.410 \mathrm{~nm})$. We emphasize that the properties of the special thin film model catalysts used for in present study favour the alloying kinetics. Compared to conventional impregnated catalysts the thin film systems are known for large and intimate contact between metal and support and defined particle size and shape (which makes them wellsuited for plan view lattice imaging by HRTEM).

The main conclusions from this work are therefore: PdZn alloy particles are thermally and structurally stable upon reduction between 473 and $873 \mathrm{~K}$. Even above $873 \mathrm{~K}$ only partial decomposition of the PdZn alloy was observed, accompanied by strong interaction with the $\mathrm{SiO}_{2}$ support and resulting in the formation of Pd-rich silicides. This broad stability range is clearly due to the strong interaction of Pd with the $\mathrm{ZnO}$ support and the high stability of the 1:1 PdZn alloy phase. The strong particle stabilization effect (SPSE) is of importance for catalytic processes such as methanol steam reforming and methanol synthesis on $\mathrm{Pd} / \mathrm{ZnO}$ catalysts. In particular, the striking differences between the $\mathrm{Pd} / \mathrm{SiO}_{2}$ and $\mathrm{Pd} / \mathrm{ZnO} / \mathrm{SiO}_{2}$ systems demonstrated in this work may lead to a better understanding of the drastic activity and selectivity differences between $\mathrm{Pd} / \mathrm{SiO}_{2}$ and $\mathrm{Pd} / \mathrm{ZnO}$ reported in the literature ${ }^{13,23}$. According to recent single crystal experiments ${ }^{33,38}$ and theory studies $^{38,39}$ it seems that this very stable PdZn alloy phase of stoichiometric surface composition is stable over a wide range of temperatures.

\section{Acknowledgement}

H. G. thanks the Max-Planck-Society for a FHI research grant 


\section{References}

[1] H. Kobayashi, N. Takezawa, C. Minochi, J. Catal. 69 (1981) 487.

[2] T.-J. Huang, S.-W. Wang, Appl. Catal. 24 (1986) 287.

[3] T.-J. Huang, S.-L. Chren, Appl. Catal. 40 (1988) 43.

[4] S. Velu, K. Suzuki, M.P. Kapoor, F. Ohashi, T. Osaki,met Appl. Catal. A 213 (2001) 47.

[5] S. Velu, K. Suzuki, M. Okazaki, M.P. Kapoor, T. Osaki, F. Ohashi, J. Catal. 194 (2000) 373.

[6] S. Murcia-Mascaro' s, R.M. Navarro, L. Gomez-Sainero,U. Costantino, M. Nocchetti,,L.G. Fierro, J. Catal. 198 (2001) 338.

[7] N. Takezawa, N. Iwasa, Catal. Today 36 (1997) 45.

[8] N. Iwasa, S. Masuda, N. Ogawa, N. Takezawa, Appl. Catal. A 125 (1995) 145.

[9] M.L. Cubeiro, J.L.G. Fierro, J. Catal. 179 (1998) 150.

[10] M.L. Cubeiro, J.L.G. Fierro, Appl. Catal. A 168 (1998) 307.

[11] Y.-H. Chin, R. Dagle, J. Hu, A.C. Dohnalkova, Y. Wang, Catal. Today 77 (2002) 79.

[12] N. Iwasa, T. Mayanagi, S. Masuda, N. Takezawa, React. Kinet. Catal. Lett. 69 (2000) 355.

[13] N. Iwasa, T. Mayanagi, W. Nomura, M. Arai, N. Takezawa, Appl. Catal. A 248 (2003)153.

[14] N. Iwasa, W. Nomura, T. Mayanagi, S. Fujita, M. Arai, N. Takezawa, J. Chem. Eng. Jpn.37 (2004) 286.

[15] Y. Suwa, S.-I. Ito, S. Kameoka, K. Tomishige, K. Kunimori, Appl. Catal. A 267 (2004) 9.

[16] R. Peters, H.G. Dunsterwald, B. Hohlein, J. Power Sources 86 (2000) 507.

[17] D.L. Trimm, Z. I. Önsan, Catal Rev. 43 (2001) 31.

[18] N. Iwasa, N. Takezawa, Top. Catal. Vol.22 3-4 (2003) 215.

[19] N. Iwasa, S. Masuda, N. Ogawa, N. Takezawa, Appl. Catal. A 125 (1995) 145.

[20] S. Liu, K. Takahashi, M. Ayabe, Catal. Today 87 (2003) 247.

[21] S. Liu, K. Takahashi, K. Uematsu, M. Ayabe, Appl. Catal. A 277 (2004) 265.

[22] N. Takezawa, N. Iwasa, Catal. Today 36 (1997) 45.

[23] N. Iwasa, T. Mayanagi, N. Ogawa, K. Sakata and N. Takezawa, Catal. Lett. 54 (1998) 119.

[24] A. Bayer, K. Flechtner, R. Denecke, H.-P. Steinrück, K.M. Neyman, N. Rösch, Surf. Sci. 600 (2006) 78.

[25] N. Iwasa, N. Ogawa, S. Masuda, N. Takezawa, Bull. Chem. Soc. Jpn. 71 (1998) 1451.

[26] S. Liu, K. Takahashi, K. Fuchigami, K. Uematsu, Appl.Catal. A 299 (2006) 58.

[27] Z.-X. Chen, K.M. Neyman, A.B. Gordienko, N. Rösch, Phys. Rev. B 68 (2003) 75417.

[28] Z.-X. Chen, K.M. Neyman, N. Rösch, Surf. Sci. 548 (2004) 291.

[29] J. Agrell, G. Germani, S.G. Järas, M. Boutonnet, Appl. Catal. A, 242 (2003) 233.

[30] Y. Suwa, S. Ito, S. Kameoka, K. Tomishige, K. Kunimori, Appl. Catal. A 267 (2004) 9.

[31] Landolt-Börnstein Vol.5 Phase Equilibria, Crystallographic and Thermodynamic Data of Binary Alloys, Springer, Berlin 1998.

[32] H. Nowotny, H. Bitter, Monatsh. Chemie 81 (1950) 679.

[33] H. Gabasch, S. Penner, B. Jenewein, B. Klötzer, A. KnopGericke, D. Wang, R. Schlögl, K. Hayek, Surface Science, submitted.

[34] G. Rupprechter, K. Hayek, L. Rendon, J.M. Yacaman, Thin Solid Films 260 (1995) 148.

[35] D. Wang, S. Penner, D.S. Su, G. Rupprechter, K. Hayek, R. Schlögl, J. Catal. 219 (2003) 434.

[36] S. Penner, D. Wang, R. Podloucky, R. Schlögl, K. Hayek, PhysChemChemPhys 6 (2004) 5244.

[37] S. Penner, B. Jenewein, H. Gabasch, B. Klötzer, D. Wang, A. Knop-Gericke, R. Schlögl, K.Hayek, unpublished work.

[38] A. Bayer, K. Flechtner, R. Denecke, H.-P. Steinrück, K. N. Neyman, N. Rösch, Surf. Sci. 600 (2006) 78.

[39] Z. Chen, K. N. Neyman, N. Rösch, Surf. Sci. 548 (2004) 291. 